\title{
"Toda vida atual é encontro": contribuições de Martin Buber para a Educação
} "All real living is meeting": contributions of Martin Buber to the field of Education "Toda vida actual es encuentro": contribuciones de Martin Buber a la Educación

Alexandra Coelho Pena $\odot$

Pontifícia Universidade Católica do Rio de Janeiro, Rio de Janeiro, RJ, Brasil.

\begin{abstract}
RESUMO
O artigo tem como objetivo apresentar os principais conceitos da obra de Martin Buber, autor da filosofia do diálogo, e suas implicações para o campo da Educação. Fortemente influenciado pelo hassidismo, Buber foi um defensor da Educação para a comunidade para se chegar à paz. O texto situa o autor na história e reflete sobre a possível filiação de sua teoria a determinados campos do conhecimento, além de abordar os conceitos centrais de sua teoria encontro dialógico, presença, relação, reciprocidade e responsabilidade, educação para a comunidade -, que contribuem para pensar a Educação nos tempos atuais, marcada pela desumanização das relações.
\end{abstract}

Palavras-chave: Martin Buber. Filosofia do diálogo. Educação.

\begin{abstract}
The article aims to present the main concepts of the work of Martin Buber, author of the philosophy of dialogue, and its implications on the field of Education. Strongly influenced by Hasidism, Buber was an advocate of education for the community to achieve peace. The text situates the author in history and reflects on the possible affiliation of his theory with certain fields of knowledge, besides addressing the central concepts of his theory - dialogical encounter, presence, relation, reciprocity and responsibility, education for the community -, that contribute to the thinking of Education in present times, marked by the dehumanization of relations.
\end{abstract}

Keywords: Martin Buber. Philosophy of dialogue. Education.

\section{RESUMEN}

El artículo tiene como objetivo presentar los principales conceptos de la obra de Martin Buber, autor de la filosofía del diálogo, y sus implicaciones para el campo de la Educación. Fuertemente influenciado por el Hassidismo, Buber fue un defensor de la Educación para la comunidad para llegar a la paz. El texto sitúa al autor en la historia y reflexiona sobre la posible filiación de su teoría a determinados campos del conocimiento, además de abordar los conceptos centrales de su teoría - encuentro dialógico, presencia, relación, reciprocidad y responsabilidad, educación para la comunidad -, que contribuyen a pensar la Educación en los tiempos actuales, marcada por la deshumanización de las relaciones.

Palabras clave: Martin Buber. Filosofía del diálogo. Educación. 


\section{ApresentaçÃo}

Martin Buber sempre se ocupou com o tema da Educação e dedicou-se a ele em vários escritos. $\mathrm{Na}$ prática, além de ter exercido a docência, foi o primeiro diretor da Escola de Formação de Educadores de Adultos, criada em 1949, em Jerusalém, chegando a defender que a educação seria um dos aspectos fundamentais da vida em comunidade para se atingir a paz vital.

O presente artigo traz a teoria de Martin Buber, filósofo do diálogo, para pensar o campo da Educação. Em um primeiro momento, o texto apresenta o contexto do início do século XX, em que Martin Buber viveu e produziu sua obra, que é esquematizada sobre três pilares: judaísmo (hassidismo), ontologia da relação e antropologia.

Após situar o autor na história e refletir sobre a possível filiação de sua teoria a determinados campos do conhecimento, são abordados os conceitos centrais da teoria de Buber, tais como encontro dialógico, presença, relação, reciprocidade e responsabilidade, educação para a comunidade entre outros, que contribuem para pensar a Educação nos tempos atuais.

\section{QUEM FOI MARTIN BUBER?}

\begin{abstract}
"Devo dizer mais uma vez: não tenho ensinamentos a transmitir. Apenas aponto algo, indico algo na realidade, algo não visto ou escassamente avistado. Tomo quem me ouve pela mão e o encaminho à janela. Escancaro-a e aponto para fora. Não tenho ensinamento algum, mas conduzo um diálogo."
\end{abstract}

(BUBER)

Filósofo? Antropólogo? Sábio? Místico? Escritor? Poeta? Mestre?

Martin Buber (1878-1965), como ele mesmo dizia, era um homem atípico e considerava um equívoco tentar classificá-lo como filósofo da linguagem, da religião ou da educação, como político ou como místico (BARTHOLO JR, 2001). Era verdadeiramente um 'Mensch'1, uma pessoa densa, que escuta, que carrega a dimensão do significado dessa palavra. Onde todos viam rupturas e separações, ele enxergava o todo e sua obra reflete essa postura ao integrar temas relativos à arte, à sociologia, à educação e à política.

A obra de Buber se apresenta sob três facetas: Judaísmo, ontologia da relação e antropologia. Da aproximação com o Judaísmo, Buber incorporou fortemente as histórias do

\footnotetext{
${ }^{1}$ Mensch tem em Buber o sentido de pessoa na sua inteireza, marcada pelo vínculo, na relação, com presença e encontro com o outro (ZUBEN, 2003a).
}

hassidismo, inserindo-se em um movimento de renovação que implica uma ontologia da relação como suporte para uma antropologia do diálogo que se desdobrou em uma ética do inter-humano (ZUBEN, 2003a).

Longe de ser um filósofo especulativo, alheio ao que se passa ao seu redor, Buber se volta para o concreto, para os acontecimentos cotidianos, para os homens e a sua ação no mundo. A sua busca pelo espiritual se dá na medida em que concebe o espiritual como intimamente entrelaçado com o mundo, com a vida, com a ação (BUBER, 2009).

Para Panko (1976), a maior contribuição de Buber, e aquela pela qual ele será lembrado por mais tempo, é na área da antropologia, pois é por entender a sua profunda preocupação com o homem que ele próprio pode ser entendido. Para Zuben (2003a), as questões antropológicas sempre ocuparam lugar central em seus pensamentos e preocupações, tanto teóricas quanto as dirigidas para a concretude da vida (PENA, 2015).

A dimensão hermenêutica está presente em toda sua obra. O problema fundamental desse modo de fazer filosofia é a busca do sentido e da interpretação, "que ultrapassa o texto escrito e se refere a uma manifestação vital que afeta as relações dos homens entre si e com o mundo" (HERMANN, 2002, p. 25). Essa perspectiva hermenêutica favoreceu a "presença de um pensamento autônomo e original com intuições originais, tanto nas suas interpretações sobre o Hassidismo quanto nas obras de caráter filosófico" (ZUBEN, 2003a, p. 15).

\section{A FORMAÇÃo de BUBER E O ENCONTRO COM O HASSIDISMO}

Para Buber, não era mais possível uma volta nostálgica à comunidade tradicional e o importante era lutar por uma comunidade nova constituída pela livre escolha, resultante de uma nova organização do trabalho, diferente tanto da aldeia rural quanto das grandes cidades. Segundo Löwy (1989), esse tipo de pensamento fez de Buber o autor mais importante e representativo do socialismo religioso na cultura judaico-alemã e um dos grandes renovadores do pensamento comunitário no século XX.

Buber estudou filosofia e história da arte na Universidade de Viena no fim do século XIX, "onde uma fervilhante vida cultural aberta a uma vasta pluralidade de influências vai mergulhá-lo num mundo de cosmopolitismo secularizado" (BARTHOLO JR, 2001, p.24). Ele estava em consonância com seu tempo, acompanhando o movimento de ocidentalização característico dos judeus de sua geração. Ele segue seus estudos como andarilho acadêmico, dedicando-se à filosofia, à filologia, germanística, história da literatura, psiquiatria e economia e, durante seus anos universitários participa do movimento sionista, muito mais em uma 
vertente cultural-espiritual do que a perspectiva políticoestatal.

É nesse contexto que Buber redescobre a tradição hassídica. Diante da possibilidade de escolher uma carreira acadêmica em quaisquer universidades alemãs, Buber escolheu voltar-se aos estudos das fontes hassídicas, resgatando laços com a sua infância vivida na companhia dos avós no interior da Polônia.

O hassidismo é um movimento judaico que floresceu no século XVIII na Polônia, cuja ideia central é a busca de um diálogo permanente entre Deus e os homens (ZUBEN, 2003a), opondo-se ao formalismo teológico e ao dogmatismo, em favor de uma religiosidade mais espontânea, marcada pela alegria e piedade. O hassidismo, que começou por abandonar o formalismo ritual, despertou maior importância ao sentimento religioso que à própria prática, proclamando a onipresença de Deus e por isso enfatiza o diálogo criativo do humano com a divindade até chegar a um êxtase que permite ao homem entrar em comunicação direta com Deus. Buber se opõe a qualquer forma antissocial de misticismo, pois, para ele, toda relação com Deus deve ser mediada pela vivência com os homens.

Do ponto de vista da tradição judaica, o hassidismo é o que mais marca a história de Buber, influenciando toda sua obra a partir da relação entre Deus e os homens. Essa relação não é falar sobre o objeto, é falar com o objeto. $\mathrm{Na}$ filosofia, Deus passa a ser objeto de conhecimento, depois uma ideia, depois um sentimento de dependência com Deus e isso vai esvaziando a relação pessoa-pessoa e Buber desejava resgatar essa relação do humano com o humano.

Desde a minha juventude fui abordado pela questão da possibilidade e realidade de uma relação dialógica entre homem e Deus, portanto de uma parceria livre do homem numa conversação entre o céu e a terra. [...] Em particular, desde que a tradição hassídica cresceu para mim até tornar-se o sustentáculo do meu próprio pensamento, isto é, desde aproximadamente 1905, esta questão passou a ser muito íntima para mim (BUBER, 2009, p. 163).

Buber reconta as histórias hassídicas em um movimento de reavivar a vivência e não de transcrevê-las, resgatando histórias esquecidas pelo tempo e recuperando a essência desse movimento não racionalista, que articula a afetividade, o corpo e o espiritual. Durante dez anos, o autor trabalhou com esse material, separando, catalogando, reformulando os ensinamentos e delineando sua própria filosofia, chegando a publicar diversos livros sobre o tema, entre os quais tem destaque "Histórias do Rabi" de 1946. A concepção buberiana de diálogo encontrou no hassidismo a fonte para o seu desenvolvimento.

\section{Do Diálogo e do DiALógico}

O século XX é considerado por muitos filósofos como o século da morte de Deus, em que a ciência e a política se desprenderam de qualquer crença e apelo ao sobrenatural. Buber chamou esse acontecimento de eclipse de Deus, uma vez que não compreendia que Deus havia sido extinto, mas que algo se interpunha entre Deus e o Homem. Desta forma, o eclipse de Deus é o reflexo do eclipse do homem, que é a preponderância quase absoluta da relação Eu-Isso, característica de uma atitude objetivadora entre os seres.

Com essa reflexão, Buber traz uma alternativa ao determinismo cartesiano. A morte é irreversível, mas um eclipse é um ocultamento passageiro. A subjetividade, elevada à categoria máxima a partir de Descartes, coloca o homem e sua racionalidade no centro da história, relegando o contato com a natureza e com o divino a um segundo plano, permitindo que esse mesmo homem estabeleça um relacionamento com coisas, que podem ser conhecidas, mas onde não há encontro. Ao retirar o homem desse isolamento, sugerindo que o EU só se constitui a partir da relação com o TU, que ele não existe sozinho, Buber (2003a) oferece a possibilidade de reatar a relação entre os homens e destes com a natureza e com o sagrado.

Buber está inserido, nesse momento da história, no evento de redescoberta do princípio dialógico, rejeitando a subjetividade solipsista e a filosofia da consciência instaurada a partir de Descartes e afirmando que o eu se torna Eu na relação com o Tu. Ele pensa o mundo a partir da relação e não do EU, pois o EU não pode ser pensado sem o TU. Isso já o torna um crítico ao pensamento cartesiano, pois não é possível pensar o eu sem o outro. Indaga: "que vem a ser, em última análise, um indivíduo?”. E ele mesmo responde:

Trata-se o indivíduo de hoje, como se fora algo facilmente acomodável, adaptável, no contexto, digamos, da causalidade científica. Creio que não se trata disso. Na minha opinião a unicidade do indivíduo, seu caráter singular que, na verdade, é incomparável, não pode ser deduzida por nenhum método científico (BUBER, 2008, p. 105).

Em 1953, Buber (2009) escreve "O social e o interhumano", fazendo uma revisão do prefácio escrito em 1905 para a coleção "Die Gesellschaft" ("A sociedade"), em que tomava esses conceitos como sinônimos. Quase cinquenta anos depois, o autor assume que essa aproximação atenuava uma linha de separação de fundamental importância entre dois domínios essencialmente diferentes do universo humano e que vão interferir diretamente em sua concepção de diálogo. Os fenômenos sociais são marcados pelas experiências em 
comum vividas por homens vinculados entre si, onde esse vínculo delimita a existência do grupo, não havendo entre os seus membros qualquer espécie de relação pessoal. Para Buber (2009), o elemento das relações pessoais tem sido afastado em proveito do elemento coletivo, sobretudo em épocas mais tardias da história humana. A coletividade liberta o homem da solidão, do medo diante do mundo e, sendo assim, o inter-humano, a vida entre pessoa e pessoa, retrai-se cada vez mais. "A esfera do inter-humano é aquela do face a face, do um-ao-outro; é o seu desdobramento que chamamos de dialógico" (BUBER, 2009, p. 138).

Os fenômenos inter-humanos não são fenômenos psíquicos; o sentido não se encontra em um dos dois parceiros, nem nos dois em conjunto, mas somente no jogo entre os dois - no "Entre". Para Von Zuben (2003b), a essência do pensamento buberiano revela-se estruturada em círculos e se caracteriza por uma ontologia da relação, na qual o "Entre" é categoria epistemológica básica. "O 'entre' é o que permite abordar o homem na sua dialogicidade; e só no encontro dialógico é que se revela a totalidade do homem" (BUBER, 2003a). Se na modernidade, há uma fértil discussão sobre o indivíduo, para Buber a crise do homem é a crise do "Entre", onde a predominância do parecer sobre o ser, a insuficiência da percepção do Outro e a imposição do modo de viver e de pensar de um homem sobre outro são fatores que, segundo o filósofo, impedem o crescimento do inter-humano:

Para isto, para a existência do inter-humano, é necessário, [...], que a aparência não intervenha perniciosamente na relação entre um ser pessoal e um outro ser pessoal; é outrossim necessário, [...], que cada um tenha o outro em mente e que o torne presente no seu ser pessoal. Que nenhum dos parceiros queira impor-se ao outro é o terceiro pressuposto básico do inter-humano (BUBER, 2009, p. 152).

Em paralelo ao conceito de inter-humano, Buber introduz a ideia de "estreita aresta", assumindo a relação dialética e rejeitando as dicotomias características do pensamento moderno e positivista. Como destaca Zuben (2003b, p. 14):

Essa metáfora, da estreita aresta, é o símbolo da unidade paradoxal daquilo que normalmente se entende por dilema ou alternativa. Rejeita uma solução tranquila para as questões humanas, o que se identificaria mais como um refúgio para espíritos pusilânimes. Nem pretende negar a existência de paradoxos e contradições, presentes em cada situação da condição humana.

Para a filosofia do diálogo, a palavra fundamenta a existência humana e a linguagem se manifesta diante de uma dupla atitude do homem frente ao mundo, por meio das palavras-princípio "Eu-Tu" e "Eu-Isso". A palavra princípio Eu-Tu fundamenta a existência em sua total atualidade, no evento da relação, da reciprocidade, da totalidade do ser, da presença; a palavra princípio Eu-Isso fundamenta a existência em sua parcialidade ou limitação, no fato da experiência, do eu egocêntrico, do objeto.

$\mathrm{Na}$ "relação" Eu-Tu existe a totalidade do ser, na "experiência" do Eu-Isso o ser não pode ser total, ele é fragmentado. O conceito de "relação" é total, é o "Entre", é a presença, é a existência, é a essência, é o inteiro, é o concreto, é sinônimo de reciprocidade. Já o conceito de "experiência" é fragmentado, é parcial, é objeto, não permite a relação, apenas o relacionamento.

A atitude Eu-Isso permite conceber o mundo a partir da sensibilidade, sendo a experiência o modo como eu entro em contato com o mundo e me utilizo dele. Já a relação Eu-Tu manifesta-se na imediaticidade, na singularidade, na intensidade, na exclusividade, na reciprocidade, na fugacidade e na presença. Buber (2003a) adverte que as duas atitudes (Eu-Tu e Eu-Isso) não podem ser confundidas nem tomadas de forma maniqueísta, cada uma tem a sua função; o problema é o predomínio crescente do relacionamento Eu-Isso em detrimento da relação $\mathrm{Eu}-\mathrm{Tu}$, que se reflete, por exemplo, na modernidade, com o crescimento descontrolado da racionalidade tecno-científica.

O mundo da experiência envolve os movimentos de contemplação e observação e o mundo da relação não renuncia aos movimentos anteriores, mas, simultaneamente, nele ocorre a tomada de conhecimento íntimo, a relação, o face a face, a exclusividade. Segundo Buber (2009), há três maneiras de perceber o outro: através da observação, da contemplação ou da tomada de conhecimento íntimo. O observador quer gravar o homem em sua mente, sendo necessária uma atenção excessiva e ater-se a tantos detalhes quanto possível. O contemplador é livre dessas "amarras" e espera despreocupado aquilo que a ele se apresentará. O observador e o contemplador têm em comum o desejo de perceber o homem que vive diante de nossos olhos; esse homem é para eles um objeto separado deles próprios e das suas vidas pessoais.

A tomada de conhecimento íntimo requer uma postura receptiva, uma disponibilidade, um aceitar, um ver o outro não como um objeto, é uma tomada de conhecimento profundo, que pode ser algo sobre mim ou pode ser algo sobre o outro:

As coisas acontecem de outra maneira quando, numa hora receptiva de minha vida pessoal, encontra-me um homem em quem há alguma coisa, que eu nem consigo captar de uma forma objetiva, que "diz algo" a mim. [...] fala algo que se introduz dentro da minha própria vida. [...] é aquela alguma coisa que o diz. [...]. Este 
homem não é meu objeto. [...] Talvez apenas tenha que aprender algo e só se trata do meu "aceitar". [...] O que importa é que eu me encarregue desse responder (BUBER, 2009, p. 42, grifo do autor).

De acordo com Buber (2009), os domínios da vida dialógica e da vida monológica não coincidem com os do diálogo e do monólogo. Para ele, existem três espécies de diálogo: o autêntico, no qual há uma reciprocidade viva entre os interlocutores, podendo ser falado ou silencioso, considerado raro pelo autor; o diálogo técnico, fruto da necessidade de um entendimento objetivo, de informação; e o monólogo disfarçado de diálogo, sobre o qual Buber $(2009$, p. 53) pondera que "não existem somente grandes esferas da vida dialógica que na sua aparência não são diálogo, mas existe também o diálogo que não é diálogo enquanto forma de vida, isto é, que tem aparência de um diálogo, mas não a sua essência".

Para Zuben (2003b), Buber construiu todo o edifício da sua obra em torno do encontro dialógico, que se fundamenta na relação, que, por sua vez, é a palavra em ato, que se expressa em múltiplos termos: diálogo, relação essencial, encontro, "Entre":

A relação mútua que tem como manifestação o contato de responsabilidade, o vínculo intersubjetivo, concretizado no contato vivido numa situação de dirigir a palavra e responder ao apelo leva a uma etapa seguinte, vale dizer, ao fenômeno da responsabilidade [...] (ZUBEN, 2003a, p. 12).

A responsabilidade, para Buber (2009), só existe onde existe o responder verdadeiro diante dos acontecimentos do cotidiano, sejam eles grandes ou pequenos. Podemos responder ao que nos acontece, ao que sentimos, vemos e ouvimos com o silêncio ou nos escondermos no hábito - ou na couraça, que tem a tarefa de repelir signos. Mas "pode acontecer, entretanto, que nos atrevamos a responder, talvez balbuciando; a alma raramente consegue alcançar uma articulação muito firme [...]. O que assim dizemos com o nosso ser é o nosso penetrar na situação" (BUBER, 2009, p. 50).

Na obra de Buber existe uma relação muito próxima entre responsabilidade e atualidade. Atualidade, atuação, atualização são termos que aparecem repetidas vezes na tradução para a língua portuguesa na obra de Buber. Na grande maioria das vezes, segundo Zuben em texto de introdução na obra de Buber (2003a), esse vocábulo não faz referência à época recente ou à contemporaneidade, mas sim à ideia de "atuar' ("wirken") que remete ao

\footnotetext{
2 Em Eu e Tu, há uma nota do tradutor sobre o termo "wirken" que aparece tantas vezes nessa obra. Para Zuben, "a autenticidade da vida enquanto atual é ser vida de encontro, assim como a autenticidade do encontro só é atingida numa vida de atualidade, de presença efetiva, atuante, visto que o autêntico encontro implica uma 'presentificação"' (2003b, p. 159).
}

conceito de presença, de ação, de responsabilidade. Por isso, toda vida atual é encontro (BUBER, 2003a), ou seja, toda vida vivida em presença, na reciprocidade, com responsabilidade possibilita o encontro. E é no encontro que nasce o sentido.

Tanto a proximidade com o hassidismo, em especial a relação entre mestre e discípulo, quanto a concepção de diálogo são importantes alicerces na construção teórica de Buber sobre a educação.

\section{Escritos SObre EduCAÇÃo}

A compreensão das concepções de Buber sobre educação implica conhecer o contexto em que esse filósofo estava inserido. Seus principais textos sobre esse tema são "Educação para a comunidade" e "Discursos sobre educação". O primeiro foi resultado de uma conferência proferida em 1929, em que o autor apostava na educação como ponto de partida para a revolução que deveria acontecer dentro de cada indivíduo, revelando o esforço de Buber para elaboração e implementação de uma nova doutrina educacional para a escola pública secundária e para a universidade, além de seu projeto para a educação de adultos. Em 1953, Buber escreve "Discursos sobre educação", reunindo três textos apresentados em conferências em diferentes estágios de seu trabalho pedagógico e que se complementam e formam uma unidade representativa de seu pensamento sobre o tema: "Discursos sobre educação", de 1925; "Formação e Cosmovisão", de 1935, e "Sobre educação do caráter", de 1939.

Liberdade e criatividade eram as palavras de ordem de uma época, em que era fundamental desenvolver uma educação "nova" e "progressista" em contraste com o "velho" e "autoritário" modelo tradicional. Conhecida como a Era da Alma (HILLIARD, 1973) essa proposta educacional tinha a atividade criadora como a característica essencial da mente humana, indo contra uma visão mecanicista e tecnológica da vida.

Buber (2003b) criticava essa nova educação centrada na criatividade do aluno - apesar de reconhecer grandes contribuições -, defendendo que, para que as forças criativas da criança se manifestem, há a necessidade, também, das forças educativas:

[...] não é à liberação de um impulso, mas sim às forças que vão ao encontro daquilo que foi liberado é que se há de atribuir a influência decisiva: às forças educacionais. Delas, de sua pureza e afetividade, de seu poder de amor e descrição depende em que ligações o elemento liberado vai agir e, com isso, o que ele se tornará (BUBER, 2003b, p. 16).

É nesse sentido que o filósofo irá se opor a uma educação baseada somente na formação do impulso 
criador, que levaria, em última instância, ao isolamento do ser humano, uma vez que esse impulso sozinho não pode conduzir à participação nem à reciprocidade. Para isso, é necessária a presença do outro, o educador (PENA, 2015).

Buber não compartilhava da concepção da educação nova sobre o papel do professor. Para ele, o professor da "velha" educação representava o mundo histórico para o aluno (relação mestre-discípulo). Apesar de considerar certos aspectos da educação nova positivos em relação à velha, não aceitava a ideia de deixar a criança se desenvolver de forma espontânea. O papel do professor não seria apenas ajudar no desenvolvimento dessa espontaneidade, mas sim selecionar o tipo de experiência desejável. De acordo com Hilliard (1973), para Buber, a criança e o professor estão juntos no centro do processo educativo.

A finalidade de toda ação educativa é a formação humana, que pressupõe a relação dialógica e que deve se dar no lugar onde se está, no cotidiano, na prática e não apenas na teoria; uma vivência concreta que se realiza nesse mundo; uma ação que auxilia a pessoa no encontro consigo mesma e com o outro. Essa concepção implica uma estreita relação entre formação e responsabilidade. "Podemos assim afirmar que o que justifica e torna indispensável a formação é a necessidade que temos de construir uma comunidade ética" (SANTIAGO; RÖHR, 2006, p. 15).

A educação para Buber (2008) é educação para a comunidade. E para compreender essa concepção e refletir sobre como ela pode ajudar a pensar a educação atual, é necessário explicitar os conceitos de "comunidade" e de "educação" para o autor.

Opondo-se às concepções de alguns pensadores que identificam comunidade com uma condição social primitiva, Buber (2008) acreditava na possibilidade de uma comunidade pós-social, que, diferentemente da pré-social fundada no parentesco de sangue, resulta de afinidades eletivas, isto é, da expressão de uma livre escolha.

Agora, quando falo de comunidade, entendo algo que abrange toda a vida, toda a existência natural do homem, não excluindo nada dela. Ou a comunidade é isso, ou, então, deve-se renunciar à ideia da existência de uma comunidade autêntica. [...]. Entendo que comunidade que se erige ao lado da vida não é comunidade (BUBER, 2008, p. 85).

Comunidade significa, assim, uma multiplicidade de pessoas, vivendo no aqui e agora, que estabelecem relações autênticas, totais ${ }^{3}$, sem almejar nenhuma finalidade, sem

\footnotetext{
3 Buber entende por totalidade a inteireza do ser humano; sua presença em corpo, mente e espírito; com responsabilidade para com o outro.
}

um 'ter em comum'; o objetivo da comunidade é estar em comunidade, é um 'estar com' de forma dinâmica, é algo que acontece entre homens em reciprocidade, sem que nada de pessoal ou objetivo se coloque entre eles. E o elemento fundamental para a construção da comunidade é a vida vivida, cotidiana, o contexto em que cada um está inserido pelo destino.

Nesse sentido, a educação, para Buber, é a preparação para o sentido de comunidade e, sendo assim, ela não pode ser teórica, ela só pode ocorrer através da comunidade, daquilo que os sujeitos experimentam juntos. Para isso, é preciso saber o que educa e quem educa. "O que educa é, em última análise, o espontâneo" (BUBER, 2008, p.90). Com isso, o autor, não está fazendo uma defesa do espontaneísmo, uma vez que o oposto de espontâneo, nesse caso, não seria o controle ou o direcionamento, mas sim a omissão (PENA, 2015). Ele acredita que o professor educa com sua presença, com sua existência pessoal, com seu exemplo, com suas perguntas e suas opiniões e influencia o aluno quando as relações entre ambos são espontâneas a ponto de o educando não saber nem perceber que está sendo educado.

A espontaneidade é, assim, o fator preponderante na educação e a formação requer o total envolvimento do educador, que precisa romper com posturas impositivas ou prescritivas, levando "o educando a mudanças na sua relação com o outro, com o mundo, levando-o a pronunciar a palavra TU, que significa formar para uma existência autêntica" (SANTIAGO; RÖHR, 2006, p.9).

É possível reconhecer na concepção de que o que educa é o espontâneo a forte influência da relação entre o mestre e discípulo trazida do hassidismo, em que o mestre, através da narração de histórias sobre líderes desse movimento, propiciava a continuação da essência sagrada e atribuía nova força ao milagre narrado. A história narrada deve, por si mesma, ser auxílio.

Nesse sentido, o educador se distingue das outras pessoas que compõem o mundo do educando pela vontade que orienta sua ação intencional de participar desse processo e, por isso, a educação é assim compreendida como responsabilidade com o outro, que é um elemento daquilo que se chama relação e que só pode acontecer onde há abertura e confiança.

A confiança é o que permite a ruptura da incomunicação e ela só é obtida na medida em que se participa imediatamente da vida dos alunos e se assume a responsabilidade que daí se deriva. A partir da confiança, o aluno sente-se incluído em uma relação dialógica e aceita o educador como pessoa, acontecendo o que Buber (2003b) chamou de encontro pedagógico.

Todo ato educativo é um ato de inclusão e, consequentemente, dialógico. Diferente da empatia, em que a pessoa sacrifica sua participação no acontecimento 
para sentir o que o outro sente, na inclusão o indivíduo participa do mesmo acontecimento junto com o outro, cada um com os seus sentimentos. Daí a inclusão ser um ato de reciprocidade.

Mas Buber (2008) não descarta do cenário da experiência educativa as tensões e os conflitos, mas sim valoriza o caráter educativo que eles podem assumir, lembrando que a finalidade da educação é o compromisso com a formação de seres capazes de estabelecer relações autênticas:

É para isso que a educação para a comunidade educa. Ela conduz, pois, dos contatos indiretos entre os homens, às relações diretas, dos contatos movidos por interesses para as relações cujo fim são elas mesmas, pois todos os falsos relacionamentos que mencionei não acontecem somente entre os adultos, mas também entre as crianças (BUBER, 2008, p. 93).

Comprometido com a ideia de pensar uma formação humana baseada em uma postura ética, Buber (2011) escreve "O caminho do homem segundo o ensinamento chassídico", contribuindo para pensar a formação de professores, que é também educação de adultos, tema ao qual o autor se dedicou profissionalmente. Neste livro, o autor, influenciado pelos sábios do hassidismo que acreditavam em Deus de uma maneira leve, reflete sobre de que maneira esses ensinamentos servem para ajudar o homem em seu caminho e organiza essa caminhada em seis passos, começando cada um deles com um conto hassídico.

O início do caminho é a autocontemplação, em que o homem se responsabiliza por seu lugar no mundo ao responder à pergunta bíblica “onde está você?”. É o homem saindo do esconderijo e observando a si próprio.

O segundo passo seria o "caminho particular" que cada homem deve seguir, na medida, em que todos os seres humanos trazem algo de novo e único ao mundo. "Essa tarefa principal é a concretização única e específica de suas potencialidades, e não a repetição de algo que um outro, ainda que seja o maior, já tenha feito" (BUBER, 2011, p. 17).

A "determinação" que caracteriza o trabalho coerente - em oposição ao trabalho malfeito -, exercido com a alma unificada anuncia o terceiro caminho, onde a tarefa deve ser feita com todos os membros do corpo, todo o ser do homem deve estar envolvido.

Para isso, o homem deve "ocupar-se consigo mesmo" nos pensamentos, na palavra e na ação para chegar ao seu eu. E aqui é importante lembrar que o eu para Buber não existe a priori, ele se constitui na relação com o outro. $\mathrm{O}$ eu que o homem precisa encontrar é o eu profundo da relação com o mundo. E, por isso, o quinto passo é "não ocupar-se consigo mesmo". Contemplar a si mesmo, encontrar seu caminho particular e unificar o seu ser não é uma ação para si mesmo, mas para se relacionar com o outro, com o mundo. E é somente "aqui onde estamos" que a existência pode ser concretizada; "aqui a vida divina, oculta, pode ser iluminada” (BUBER, 2011, p. 54).

\section{CONSIDERAÇões FINAIS}

Atualmente, a educação enfrenta os desafios da violência, da medicalização e da discussão de gênero, para citar alguns. Assuntos que são, muitas vezes, deslocados das escolas para as mãos de especialistas, que podem reduzi-los a questões de ordem biológica e, portanto, tratadas pela ótica do desvio e por uma visão médica, esquecendo-se de problematizar a forma como acontecem as relações entre as pessoas nas escolas.

As contribuições de Martin Buber para a educação caminham no sentido de ajudar a compreender as relações que se estabelecem no interior das instituições educativas, onde, muitas vezes, os elos entre as pessoas estão desumanizados e marcados por atitudes de confronto, intolerância e rejeição (KRAMER, 2013). Onde, alunos e professores são, frequentemente, vistos de forma fragmentada: ora valorizando aspectos cognitivos, ora questões morais, ou ainda só como corpos a serem contidos e docilizados. Adultos com medo de exercer autoridade e dar limites, crianças e jovens instáveis e inseguros.

Transformar esse outro de quem eu falo naquele com quem eu falo é o desafio da educação em qualquer segmento. Ver, escutar, aceitar, acolher, ter atenção e autoridade são tarefas do professor de crianças, jovens e adultos em que predomine a dimensão humana sobre a utilitária, em que prevaleça uma ética do cuidado com o outro, constituída pelo encontro, pela presença e pela responsabilidade.

\section{REFERÊNCIAS}

BARTHOLO JR., R. Você e eu: Martin Buber, presença palavra. Rio de Janeiro, Garamond, 2001.

BUBER, M. Do diálogo e do dialógico. São Paulo: Perspectiva, 2009.

BUBER, M. El camino del ser humano y otros escritos. Madrid: Fundación Emmanuel Mounier, 2003 b.

BUBER, M. Eu e tu. São Paulo: Centauro, 2003a.

BUBER, M. Histórias do Rabi. São Paulo: Perspectiva, 2013.

BUBER, M. O caminho do homem segundo o ensinamento chassídico. São Paulo: Realizações, 2011. 
BUBER, M. Sobre comunidade. São Paulo: Perspectiva, 2008 .

HERMANN, N. Hermenêutica e educação. Rio de Janeiro: DP\&A, 2002.

HILLIARD, F. H. A re-examination of Buber's address on education. British Journal of Educational Studies, Oxford, v. 21, n. 1, p. 40-49, 1973. https://doi.org/10.1080/00071005.1 973.9973364

KRAMER, S. Contribuições de Martin Buber para a reflexão sobre/do homem contemporâneo. In: LEWIN, H. Judaísmo e cultura: fronteiras em movimento. Rio de Janeiro:

Imprimatur, 2013.

LÖWY, M. Redenção e utopia: o judaísmo libertário na

Europa Central. São Paulo: Companhia das Letras, 1989.

PANKO, S. Makers of the modern theological mind: Martin Buber. Texas: Word Books, 1976.

PENA, A. C. Para explicar o presente tem que estudar a história do passado: narrativas de profissionais de escolas comunitárias de Educação Infantil da Baixada Fluminense. 2015. Tese (Doutorado em Educação) - Programa de Pós-Graduação em Educação, Departamento de Educação, Pontifícia Universidade Católica do Rio de Janeiro, Rio de Janeiro, 2015. https://doi.org/10.17771/pucrio.acad.25918

SANTIAGO, M. B. N.; RÖHR, F. Formação e diálogo nos discursos de Martin Buber. In: REUNIÃO ANUAL DA ANPED, 29., 2006, Caxambu. Trabalho apresentado [...]. Caxambu: ANPED, 2006.

ZUBEN, N. A. V. Introdução. In: BUBER, M. Eu e tu. São Paulo: Centauro, 2003b.

ZUBEN, N. A. V. Martin Buber: cumplicidade e diálogo. Bauru: EDUSC, 2003a.

Recebido em: 6/2/2018.

Aprovado em: 1/8/2019.

Publicado em: 5/11/2019.

Endereço para correspondência:

Alexandra Coelho Pena

Rua Marquês de São Vicente, 225, prédio Cardeal Leme, s. 1060 - Gávea

22451-900, Rio de Janeiro, RJ, Brasil

\section{Autora:}

Alexandra Coelho Pena

Doutora em Educação pela Pontifícia Universidade Católica do Rio de Janeiro

(PUC-Rio). Professora no Departamento de Educação da PUC-Rio, Rio de Janeiro, RJ, Brasil.

Orcid: http://orcid.org/0000-0003-3363-6059

E-mail: alexandracpena@yahoo.com.br 